\title{
Factors associated with zinc utilization for the management of diarrhea in under-five children in Ethiopia
}

\author{
Achamyeleh Birhanu Teshale* ${ }^{*}$, Alemneh Mekuriaw Liyew and Getayeneh Antehunegn Tesema
}

\begin{abstract}
Background: Zinc has a tremendous advantage to save the life of children. It reduces the mean duration of diarrhea and mortality due to diarrhea. Besides, it reduces the severity of the initial episode, and also it prevents future diarrhea episodes. But there is low utilization of zinc for the management of diarrhea in under-five children in Ethiopia and there is a paucity of literature regarding the factors associated with the utilization.

Method: The 2016 Ethiopian demographic and health survey data were used as a data source. A total weighted sample of 1228 under-five children with diarrhea within 2 weeks preceding the survey were used. A mixed-effects logistic regression analysis was done to account for the complex sample design of the data. Variables with $p$-value $<0.20$ in the bivariable analysis were eligible for multivariable analysis and those variables with $p$ value $<0.05$ in the multivariable analysis were declared to be determinants of zinc utilization for the management of diarrhea in under-five children.

Result: In this study, we found multiple determinants of zinc utilization. Mothers with formal education (adjusted odds ratio $(A O R)=1.83 ; 95 \% \mathrm{Cl} ; 1.30-2.58)$ and media exposure $(\mathrm{AOR}=1.46 ; 95 \% \mathrm{Cl} ; 1.04-2.04)$ had higher odds of zinc utilization. But mothers from five and above household size (AOR $=0.57 ; 95 \% \mathrm{Cl} ; 0.39-0.82$ ) had lower odds of zinc utilization for the management of diarrhea in under-five children.

Conclusion: In our study maternal education, media exposure, and household size were determinants of zinc utilization for the management of diarrhea in under-five children. Being having a formal education and being exposed to all or either of the three media (radio, TV, and newspaper) increases the likelihood of zinc utilization while being mothers from large household size decreases the likelihood of zinc utilization. Therefore, giving special attention to those mothers with no formal education, and mothers from high family size could increase the utilization of zinc for the management of diarrhea in under-five children. Also, media campaigns regarding diarrhea management could be scaled up to potentially achieve the desired impact.
\end{abstract}

Keywords: Zinc utilization, Diarrhea, Under-five children, Ethiopia

\section{Background}

In low- and middle-income countries there is a continuing inadequate safe water and sanitation which makes diarrhea the leading cause of death among under-five children $[1,2]$. Despite the availability of simple and

\footnotetext{
*Correspondence: achambir08@gmail.com

Department of Epidemiology and Biostatistics, Institute of Public Health, College of Medicine and Health Sciences, University of Gondar, Gondar, Ethiopia
}

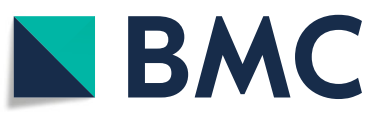

(c) The Author(s). 2020 Open Access This article is licensed under a Creative Commons Attribution 4.0 International License, which permits use, sharing, adaptation, distribution and reproduction in any medium or format, as long as you give appropriate credit to the original author(s) and the source, provide a link to the Creative Commons licence, and indicate if changes were made. The images or other third party material in this article are included in the article's Creative Commons licence, unless indicated otherwise in a credit line to the material. If material is not included in the article's Creative Commons licence and your intended use is not permitted by statutory regulation or exceeds the permitted use, you will need to obtain permission directly from the copyright holder. To view a copy of this licence, visit http://creativecommons.org/licenses/by/4.0/ The Creative Commons Public Domain Dedication waiver (http://creativecommons.org/publicdomain/zero/1.0/) applies to the data made available in this article, unless otherwise stated in a credit line to the data. effective treatment for diarrhea, around $8 \%$ of all deaths among under-five children were due to diarrhea in 2017. This means approximately 1300 children each day or 480,000 under-five children in a year were died due to diarrhea [3].

Since 2004, the United Nations Children's Fund (UNICEF) and the World Health Organization (WHO) have recommended continued feeding, oral rehydration salts, and zinc supplements as management of childhood 
diarrhea [4]. Starting from this time zinc is used for the management of diarrhea with tremendous advantage to save the life of children. It reduces the mean duration of diarrhea by $19.7 \%$, mortality due to diarrhea by $23 \%$, and reduces the severity of the initial episode and subsequent diarrhea episodes in the 2-3 months following supplementation [5-7]. In addition, zinc is a trace element essential for a healthy immune system and its deficiency can make a person more susceptible to illness and disease $[8,9]$. Since zinc is not stored in the body, the level of zinc is associated with dietary intake, absorption, and losses. That is zinc deficiency states may exist in children with acute diarrhea as a result of intestinal loss [10, 11]. Using zinc for the treatment of acute diarrhea helps to strengthen the immune function and intestinal structure, as well as the epithelial recovery process [12].

In addition to its effect on diarrhea, zinc supplementation had a paramount advantage to reduce respiratory illnesses (pneumonia and acute lower respiratory tract infections) and malaria among children [13-16]. For example, zinc deficiency is associated with approximately 800,000 excess deaths of under-five children throughout the world, of these 176, 000, 406, 000, and 207,000 deaths were attributable to diarrhea, pneumonia, and malaria respectively [17].

In Africa, the prevalence of good diarrhea management (using oral rehydration therapy, zinc, continued feeding with increased frequency) is low which ranges from $17 \%$ in Cote d'Ivoire to $38 \%$ in Niger [18]. Other studies in Nepal and Kenya revealed that only 15 and $18 \%$ of caregivers/mothers give zinc for the management of diarrhea for their sick child respectively $[19,20]$. In Ethiopia, 46 and 33\% of under-five children with diarrhea received oral rehydration therapy and zinc respectively and only $17 \%$ received a combination of these [21].

Pieces of literatures indicated that mass media exposure, maternal education, distance from the health facility, and maternal occupation are some of the factors that are associated with zinc utilization for the management of diarrhea among under-five children [20, 22-27].

Even though zinc has paramount advantages, as shown above, the utilization of zinc for the management of diarrhea in under-five children in Ethiopia is very low [21]. There is a paucity of literature regarding factors associated with this low zinc utilization for the management of diarrhea in Africa. Up to our knowledge, there was no study done regarding the factors associated with zinc utilization for the management of diarrhea in Ethiopia. Therefore, this study was aimed to assess the factors associated with zinc utilization for the management of diarrhea in under-five children in Ethiopia. The findings of this study could give insights for policymakers, health professionals, and the community in general for appropriate management of such fearful childhood illness, which is particularly common in countries with poor clinical settings like Ethiopia.

\section{Method \\ Study design and setting}

A population-based cross-sectional study was conducted in Ethiopia, which is one of the most populous African country next to Nigeria. Ethiopia is administratively classified into nine regions and two city administrations. These regions are further classified into zones, woredas, and kebeles hierarchically. Ethiopia covers $1,104,300 \mathrm{~km}^{2}$ with a population of around 114 million. Most (79\%) of the population of Ethiopia are rural dwellers and the total fertility rate is 4.3 live births per reproductive-age women.

\section{Data source}

The 2016 EDHS, the fourth survey conducted between January 18, 2016, to June 27, 2016, was used for this study after getting approval from the Measure DHS program through a legal request using the website https:// dhsprogram.com.

\section{Study population and sampling procedures}

The 2016 EDHS sample was selected in two stages. In the first stage, 202 clusters in urban areas and 443 clusters in rural areas were selected by using 84,915 enumeration areas from the 2007 population housing census as a sampling frame. In the second stage, a total of 28 households were selected after the household listing was carried out per each cluster. For this study, from the births data set, 10,641 total deliveries within 5 years preceding the survey were used as a target population. Several exclusion criteria were used to reach the final sample for this study. Then, a total weighted sample of 1228 living children with diarrhea within 2 weeks preceding the survey were included in the final analysis (Fig. 1).

\section{Study variables}

The outcome variable for this study was the utilization of zinc for the management of diarrhea which was a binary outcome variable coded as " 0 " for No, and " 1 " for Yes. The independent variables included were media exposure, maternal education, maternal age, maternal occupation, marital status, religion, wealth status, health insurance coverage, parity, household size, sex of the household head, wanted the last child, perception of distance from the health facility, residence, and region. For this study, media exposure was created from three variables; frequency of watching TV, reading a newspaper, and listening radio and coded as yes if an individual was exposed to all or either of the three and no if an individual was not exposed to at least one of these. In addition, 


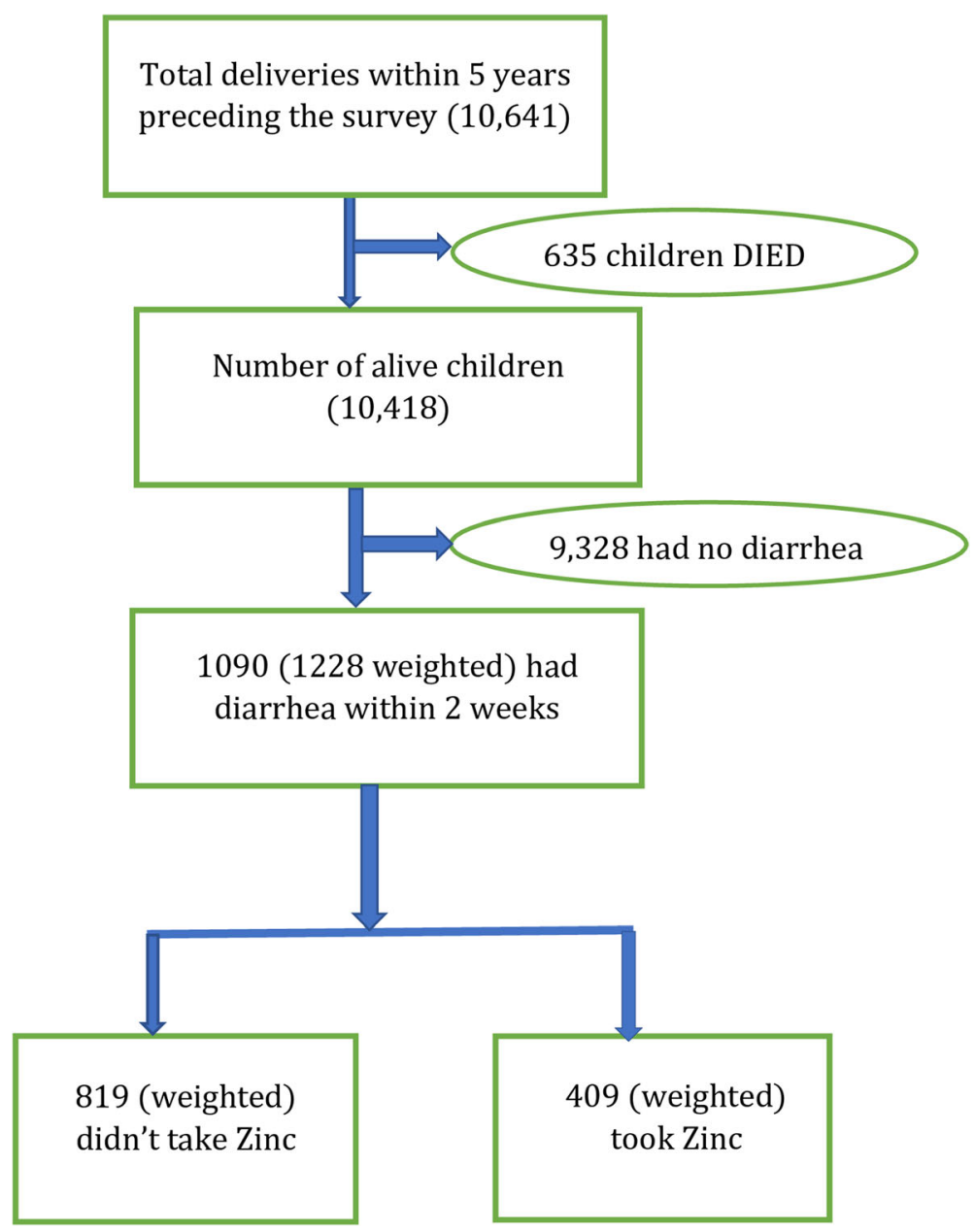

Fig. 1 Schematic presentation of under-five children with diarrhea included in the study

region was recoded into three categories as; small peripheral regions (Afar, Somali, Benishangul, and Gambela), large central regions (Tigray, Amhara, Oromia, and Sothern Nations Nationalities and Peoples Region), and metropolitans (Harari, Dire Dawa, and Addis Ababa), based on their geopolitical features similar to another study [28].

\section{Data processing and analysis}

We extracted the data from EDHS 2016 and further coding and analysis were done using Stata version 14. Sampling weight was done to adjust disproportionate sampling and non-response, as well as to restore the representativeness of the sample. Descriptive statistics were done using frequency and percentage distributions. We used the mixed-effects logistic regression model approach under the generalized linear mixed model (GLMM) framework to account for the complex sample survey design. Besides, the intraclass correlation coefficient (ICC) was calculated to show whether there was a difference in zinc utilization between clusters, and model comparison was done using deviance. Both bivariable and multivariable mixed effect logistics regression model was fitted and variables with $p<0.2$ in the bivariable analysis were eligible for multivariable analysis. In the multivariable analysis variables with $p<0.05$ were declared to be significant factors associated with zinc utilization. Variance inflation factor (VIF) was used to test if independent variables were correlated (multicollinearity).

\section{Results}

\section{Sociodemographic characteristics}

The total weighted sample size used for our analysis was 1228 under-five children who had diarrhea within 2 weeks preceding the survey. The median age of the study participants was 28 (IQR $=24-33$ ) years with the majority $(29.41 \%)$ in the age group 25 to 29 . A majority $(62.46 \%)$ of mothers had no formal education and 94.27\% were got married. Regarding media exposure, $65.27 \%$ of mothers had not exposed to either of the three media (radio, TV, and newspaper). More than 
two-thirds of study participants were from households with five and above household size and $88.43 \%$ of the respondents were from male-headed households. Looking at residence, $89.73 \%$ of the study participants were rural dwellers (Table 1).

\section{Random effect and model comparison}

We used the intraclass correlation coefficient (ICC) to assess the random or clustering effect and deviance, others as supportive, for model comparison. The ICC in the null model was 0.185, indicating that about $18.5 \%$ of the total variation in zinc utilization was attributable to unmeasured or unmeasurable factors (random effects) and this variation was significant. Regarding model comparison, the final model (a model with lower deviance) was the best-fitted model (Table 2).

\section{Factors associated with zinc utilization}

In the bivariable analysis variables like religion, marital status, maternal occupation, wealth status, sex of the household head, and wanted the last child had $p$ value $\geq 0.20$ and they were not eligible for multivariable analysis. In the multivariable analysis, maternal education, media exposure, and household size were found to be significant determinants of zinc utilization for diarrhea management in under-five children at $\mathrm{p}$-value $<0.05$. The odds of zinc utilization during diarrheal illness was 1.83 (adjusted odds ratio $(\mathrm{AOR})=1.83 ; 95 \% \mathrm{CI} ; 1.30-2.58)$ times higher among mothers who had formal education as compared to mothers with no formal education. Mothers who were exposed to either of the three media (radio, TV, or newspaper) had 1.46 ( $\mathrm{AOR}=1.46 ; 95 \% \mathrm{CI}$; 1.04-2.04) times higher odds of zinc utilization for diarrhea management as compared to those mothers who were not exposed to at least one of these media. Moreover, the odds of zinc utilization among mothers from the household size of five and above were decreased by $43 \%$ (AOR = 0.57;95\% CI; 0.39-0.82) as compared to mothers from a household size of below five (Table 3 ).

\section{Discussion}

Although zinc is included as the management option of diarrhea among under-five children, in Ethiopia a small proportion of women with under-five children used zinc for the management of diarrhea. In this study, we assessed the factors associated with zinc utilization for the management of diarrhea in under-five children using a mixed-effects logistic regression model. We found maternal education, media exposure, and household size as determinants of zinc utilization during diarrheal illness in under-five children.
The odds of zinc utilization during diarrheal illness in under-five children were higher among children whose mothers had formal education as compared to their counterparts. This is in line with a study done in North-Western Nigeria on the use of zinc in under-five children with diarrhea [25]. This might be due to educated mothers might have awareness regarding their child's health and they might be active to take their sick child to the nearest health facility. This, in turn, might create an opportunity for mothers to get advice from health professionals and give the recommended or the prescribed medication including zinc for their sick child.

Consistent with studies done in Bangladesh [24], Nepal [20], India [27], and Ghana [23], in this study the likelihood of using zinc for the management of diarrhea in under-five children was higher among mothers who had media exposure as compared to mothers with no media exposure. This might be because of advertising through both television and radio regarding zinc syrup or tablets are the quickest media channels in terms of creating or disseminating information on the benefits of zinc in the country. Also, even though in Ethiopia reading newspapers is not common, reading newspapers and posted materials around the pharmacy might have a great advantage for understanding zinc as an important component for the management of diarrhea in under-five children. These all can result in a great opportunity for creating awareness for caregivers/mothers to give this very important micronutrient for her sick child.

Moreover, mothers with higher household members (five or above) had lower odds of giving zinc to their child with diarrhea as compared to mothers from less than five household members. This might be because mothers with larger household sizes might be busy by many routine activities and they are unable to give appropriate care for her sick child. In addition, mothers from large household sizes might have parenting stress which might affect appropriate child feeding practices and health-seeking behavior to get treatment if their child becomes sick.

The clinical and public health implication of this study is to enhance zinc utilization for the management of diarrhea in under-five children by identifying the factors attributed to the low utilization. Therefore, considering and taking special attention of factors that favor the low utilization of zinc for the management of diarrhea among under-five children such has mothers having no formal education, mothers have no exposure to media, and mothers from large household size could increase zinc utilization.

This study had both strengths and limitations. The strength of this study is just it is based on nationally 
Table 1 Sociodemographic characteristics of study participants

\begin{tabular}{c}
\hline Variables \\
\hline Materna \\
$15-19$ \\
$20-24$ \\
$25-29$ \\
$30-34$ \\
$35-39$ \\
$40-44$ \\
$45-49$
\end{tabular}
Weighted frequency percentage

Maternal age

15-19 43

263

$20-24$

361

$30-34$

311

164

68

45-49

18

Maternal education

Have no formal education $\quad 767$

Have formal education $\quad 461$

Marital status

Unmarried

Married

Religion

\section{Orthodox}

Protestant

Muslim

Others $^{a}$

Maternal occupation

Not working

Working

Wealth status

Poor

Middle

Rich

Media exposure

No

Yes

Health insurance coverage

No
Yes
Parity

Primiparous

Multiparous

Grand multiparous

Wanted the last child

$\begin{array}{ll}\text { No } & 370 \\ \text { Yes } & 858\end{array}$

Household size

$$
<5
$$$$
\geq 5
$$

846

Sex of household head

Male
3.53

21.44

29.41

25.29

13.36

5.51

1.45

62.46

37.54

5.73

94.27

36.71

25.57

34.95

2.77

52.82

47.18

43.81

21.79

34.40

65.27

34.73
Table 1 Sociodemographic characteristics of study participants (Continued)

\begin{tabular}{lll}
\hline Variables & Weighted frequency & percentage \\
\hline Female & 142 & 11.57 \\
Distance from the health facility & & \\
Not a big problem & 512 & 41.72 \\
Big problem & 716 & 58.28 \\
Residence & & \\
Urban & 126 & 10.27 \\
Rural & 1102 & 89.73 \\
Region & & \\
Large central & 1147 & 93.47 \\
Small peripheral & 55 & 4.45 \\
Metropolitan & 26 & 2.08 \\
\hline
\end{tabular}

${ }^{a}$ catholic, traditional, and other

representative data with appropriate analysis techniques. This study is also the first to assess the determinants of zinc utilization in under-five children during diarrheal illness in Ethiopia. Since there was a paucity of literatures/studies done before, we have got difficulty in discussing our findings by comparing it with other studies. Also, mothers/caregivers were asked to remember "whether she gave zinc while her child got diarrhea" there may be a lapse of memory or recall bias. Moreover, due to the cross-sectional nature of the data clear temporality (cause and effect relationship) was not established between the dependent and independent variables.

\section{Conclusion}

We found multiple determinants of zinc utilization for the management of diarrhea in under-five children. These factors are; maternal education, media exposure, and household size. Being having a formal education and media exposure increases the odds of zinc utilization and being mothers from larger household sizes decreases the odds of zinc utilization for the management of diarrhea in under-five children. Therefore, media campaigns regarding diarrhea management

Table 2 Random effect and model comparison for factors associated with zinc utilization

\begin{tabular}{lll}
\hline Parameter & Null model & Final model \\
\hline ICC (\%) & $18.5(10.4-30.7)$ & $12.9(5.7-26.4)$ \\
AIC & 1422.076 & 1381.848 \\
LL & -709.038 & -672.924 \\
Deviance & 1418.076 & 1345.848 \\
\hline
\end{tabular}

AIC Akaike Information criteria, LL Loglikelihood 
Table 3 Factors associated with zinc utilization for management of diarrhea among under-five children, EDHS 2016

\begin{tabular}{|c|c|c|c|c|}
\hline \multirow[t]{2}{*}{ Variables } & \multicolumn{2}{|c|}{ Zinc utilization during Diarrhea } & \multicolumn{2}{|c|}{ Odds Ratio $(95 \% \mathrm{Cl})$} \\
\hline & No & Yes & COR & AOR \\
\hline \multicolumn{5}{|l|}{ Maternal age } \\
\hline $15-19$ & 24 & 19 & 1.00 & 1.00 \\
\hline $20-24$ & 167 & 96 & $1.00(0.48-2.08)$ & $1.04(0.48-2.22)$ \\
\hline $25-29$ & 233 & 128 & $0.70(0.34-1.44)$ & $0.84(0.38-1.85)$ \\
\hline $30-34$ & 233 & 78 & $0.54(0.26-1.14)$ & $0.80(0.34-1.89)$ \\
\hline $35-39$ & 100 & 64 & $0.74(0.34-1.59)$ & $1.17(0.47-2.89)$ \\
\hline $40-44$ & 50 & 18 & $0.56(0.22-1.43)$ & $0.97(0.33-2.78)$ \\
\hline $45-49$ & 11 & 7 & $0.67(0.16-2.74)$ & $1.42(0.32-6.19)$ \\
\hline \multicolumn{5}{|l|}{ Maternal education } \\
\hline Have no formal education & 566 & 201 & 1.00 & 1.00 \\
\hline Have formal education & 253 & 208 & $2.39(1.79-3.21)$ & $1.83(1.30-2.58) * *$ \\
\hline \multicolumn{5}{|l|}{ Media exposure } \\
\hline No & 575 & 226 & 1.00 & 1.00 \\
\hline Yes & 244 & 183 & $2.06(1.53-2.76)$ & $1.46(1.04-2.04) *$ \\
\hline \multicolumn{5}{|l|}{ Health insurance coverage } \\
\hline No & 797 & 390 & 1.00 & 1.00 \\
\hline Yes & 22 & 19 & $1.81(0.83-3.94)$ & $1.58(0.72-3.48)$ \\
\hline \multicolumn{5}{|l|}{ Parity } \\
\hline Primiparous & 146 & 81 & 1.00 & 1.00 \\
\hline Multiparous & 341 & 196 & $0.75(0.51-1.11)$ & $1.30(0.82-2.04)$ \\
\hline Grand multiparous & 332 & 132 & $0.52(0.35-0.78)$ & $1.40(0.76-2.59)$ \\
\hline \multicolumn{5}{|l|}{ Household size } \\
\hline$<5$ & 234 & 148 & 1.00 & 1.00 \\
\hline$\geq 5$ & 586 & 260 & $0.51(0.38-0.69)$ & $0.57(0.39-0.82) * *$ \\
\hline \multicolumn{5}{|l|}{ Distance from the health facility } \\
\hline Not a big problem & 327 & 185 & $1.70(1.27-2.27)$ & $1.28(0.95-1.74)$ \\
\hline Big problem & 493 & 223 & 1.00 & 1.00 \\
\hline \multicolumn{5}{|l|}{ Residence } \\
\hline Urban & 62 & 64 & 1.00 & 1.00 \\
\hline Rural & 757 & 345 & $0.37(0.25-0.55)$ & $0.71(0.44-1.14)$ \\
\hline \multicolumn{5}{|l|}{ Region } \\
\hline Large central & 770 & 377 & 1.00 & 1.00 \\
\hline Small peripheral & 34 & 21 & $1.20(0.85-1.70)$ & $131(0.92-1.87)$ \\
\hline Metropolitan & 15 & 11 & $2.02(1.28-3.19)$ & $1.43(0.88-2.32)$ \\
\hline
\end{tabular}

AOR Adjusted Odds Ratio, COR Crude Odds Ratio, ${ }^{*}=P<0.05,{ }^{* *}=p<0.01$

options could be scaled up to potentially increase zinc utilization. Also, giving special attention to those mothers with no formal education and mothers from large household sizes could increase the utilization of zinc for the management of diarrhea in under-five children.

\section{Abbreviations}

AOR: Adjusted Odds Ratio; AIC: Akaike Information criteria; Cl: Confidence Interval; EDHS: Ethiopian Demographic and Health Survey; DHS: Demographic and Health Survey; GLMM: Generalized Linear Mixed Model; ICC: Intra Class Correlation; LL: Loglikelihood; UNICEF: United Nations Children's Fund; VIF: Variance Inflation Factor; WHO: World Health Organization

\section{Acknowledgments}

Our deepest gratitude and appreciation go to the measure DHS program for allowing us to use this survey data.

\section{Authors' contributions}

ABT, GAT initiated the research concept, analyzed the data, presented and interpreted the results, and wrote up the draft manuscript. AML involved in 
data analysis and reviewed the manuscript document. All authors read and approved the final manuscript.

\section{Funding}

No, any funding was received from any organization.

\section{Availability of data and materials}

We included all result-based data within the manuscript and the data set can be accessed online from www.measuredhs.com/data.

\section{Ethics approval and consent to participate}

Since we used Publicity available data set, ethical approval was not as such required. But we accessed the data set from the DHS website (https:// dhsprogram.com// through registering or online requesting. This study was deemed exempt by the Institutional Review Committee of Institute of Public Health, College of Medicine and Health Sciences, University of Gondar.

\section{Consent for publication}

Not applicable.

\section{Competing interests}

The authors declare that they have no competing interests.

\section{Received: 7 April 2020 Accepted: 14 September 2020}

Published online: 24 September 2020

\section{References}

1. Organization WH. Preventing diarrhea through better water, sanitation and hygiene: exposures and impacts in low- and middle-income countries; 2014. p. 48.

2. Dutta P, Dutta S. Acute diarrhoea in children in: Banerjee S, editor. Textbook of community and social Paediatrics. 2nd ed. New Delhi: Jaypee Brothers Medical Publishers LTD; 2008

3. UNICEF. Monitoring the situation of children and women. Diarrhoea remains a leading killer of young children, despite the availability of a simple treatment solution. 2019.

4. WHO/UNICEF Joint Statement. Clinical management of acute diarrhea. 2004

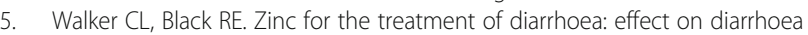
morbidity, mortality and incidence of future episodes. Int J Epidemiol. 2010; 39(Suppl 1):i63-9.

6. Patel A, Mamtani M, Dibley MJ, Badhoniya N, Kulkarni H. Therapeutic value of zinc supplementation in acute and persistent diarrhea: a systematic review. PLoS One. 2010;5(4):e10386.

7. The Zinc Investigators' Collaborative Group. Therapeutic effects of oral zinc in acute and persistent diarrhea in children in developing countries: pooled analysis of randomized controlled trials. Am J Clin Nutr. 2000;72:1516-22.

8. Nordqvist J. What are the health benefits of zinc? 2017.

9. Debjit Bhowmik, Chiranjib, KP Sampath Kumar. A potential medicinal importance of zinc in human health and chronic disease. Int J Pharm Biomed Sci 2010;1(1):05-11.

10. Hoque KM, Binder HJ. Zinc in the treatment of acute diarrhea: current status and assessment. Gastroenterology. 2006;130(7):2201-5.

11. Roohani N, Hurrell R, Kelishadi R, Schulin R. Zinc and its importance for human health: An integrative review. J Res Med Sci. 2013;18(2):144-57.

12. World Health Organization, UNICEF. Implementing the new recommendations on the clinical management of diarrhoea. Guidelines for policy makers and programme managers. Geneva: WHO; 2006.

13. Abdullah Brooks W, Santosham M, Naheed A, Doli G, Abdul Wahed M, Diener-West $M$, et al. Effect of weekly zinc supplements on incidence of pneumonia and diarrhoea in children younger than 2 years in an urban, low-income population in Bangladesh: randomised controlled trial. Lancet. 2005;366:999-1004.

14. The Zinc Against Plasmodium Study Group. Effect of zinc on the treatment of Plasmodium falciparum malaria in children: a randomized controlled trial. Am J Clin Nutr. 2002;76:805-12.

15. Shankar AH, Genton B, Baisor M, Paino J, Tamja S, Adiguma T, et al. The influence of zinc supplementation on morbidity due to Plasmodium falciparum: a randomized trial in preschool children in Papua New Guinea. Am J Trop Med Hyg. 2000;62(6):663-9.

16. Yakoob MY, Theodoratou E, Jabeen A, Imdad A, Eisele TP, Ferguson J, et al. Preventive zinc supplementation in developing countries: impact on mortality and morbidity due to diarrhea, pneumonia and malaria. BMC Public health. 2011:11(3):S23.

17. Ezzati M, Lopez AD, Rodgers A, Murray CJ. Comparative quantification of health risks. Global and regional burden of disease attributable to selected major risk factors, vol. 2004. Geneva: World Health Organization; 2004. p. 1651-801.

18. Carvajal-Velez L, Amouzou A, Perin J, Maiga A, Tarekegn H, Akinyemi A, et al. Diarrhea management in children under five in sub-Saharan Africa: does the source of care matter? A Countdown analysis. BMC Public Health. 2016;16:830.

19. Lam F, Wentworth L, Cherutich P, Migiro S, Abdala K, Musyoka M, et al. An evaluation of a national oral rehydration solution and zinc scale-up program in Kenya between 2011 and 2016. J Glob Health. 2019;9(1):010505.

20. Wang W, MacDonald M. Introducing zinc through the private sector for the treatment of childhood diarrhea: results from a Populationbased survey in Nepal. The Social Marketing Plus for Diarrheal Disease Control: Point-of-Use Water Disinfection and Zinc Treatment (POUZN) Project, Abt Associates Inc. 2009

21. Ethiopia CS, Macro OR. Ethiopia demographic and health survey. Addis Ababa: Central Statistical Agency; 2016.

22. Larson CP, Saha UR, Nazrul H. Impact monitoring of the national scale up of zinc treatment for childhood diarrhea in Bangladesh: repeat ecologic surveys. PLoS Med. 2009;6(11):e1000175

23. El-Khoury M, Banke K, Sloane P. Improved childhood diarrhea treatment practices in Ghana: a pre-post evaluation of a comprehensive private-sector program Global Health. Sci Practice. 2016:4(2):264-75.

24. Alam Z, Higuchi M, Sarker MAB, Hamajima N. Mass media exposure and childhood diarrhea: a secondary analysis of the 2011 Bangladesh demographic and health survey. Nagoya J Med Sci. 2019;81(1):31-40.

25. Gwarzo GD. Mothers' awareness and use of zinc in under-five children with diarrhoea in North-Western Nigeria. Nigerian J Paediatrics. 2018;45(2):81-5.

26. Ajayi DT, Bello O, ljaola TT, Oke OA, Fabiyi GA. Determinants of Oral Rehydration Solution and Zinc Use Among Under-Five Children for The Management of Diarrhea in Abeokuta, Nigeria. Archives Basic Applied Med. 2019;7(1):35-9.

27. Lam F, Pro G, Agrawal S, Shastri VD, Wentworth L, Stanley M, et al. Effect of enhanced detailing and mass media on community use of oral rehydration salts and zinc during a scale-up program in Gujarat and Uttar Pradesh. Glob Health. 2019:9(1):010501.

28. Ahmed KY, Page A, Arora A, Ogbo FA. Trends and determinants of early initiation of breastfeeding and exclusive breastfeeding in Ethiopia from 2000 to 2016. Int Breastfeed J. 2019:14:40.

\section{Publisher's Note}

Springer Nature remains neutral with regard to jurisdictional claims in published maps and institutional affiliations.
Ready to submit your research? Choose BMC and benefit from:

- fast, convenient online submission

- thorough peer review by experienced researchers in your field

- rapid publication on acceptance

- support for research data, including large and complex data types

- gold Open Access which fosters wider collaboration and increased citations

- maximum visibility for your research: over $100 \mathrm{M}$ website views per year

At BMC, research is always in progress.

Learn more biomedcentral.com/submission 